\title{
PERANCANGAN DUALBAND BANDPASS FILTER DENGAN METODE SQUARE OPEN LOOP RESONATOR PADA FREKUENSI $2100 \mathrm{MHz}$
}

\author{
Agnes Yora Gracia Simatupang*), Teguh Prakoso, dan Imam Santoso \\ Departemen Teknik Elektro, Universitas Diponegoro \\ J1. Prof. Sudharto, SH, Kampus UNDIP Tembalang, Semarang 50275, Indonesia \\ ${ }^{*}$ Email: agnes_yora@hotmail.com
}

\begin{abstract}
Abstrak
Tapis (filter) merupakan komponen yang berperan penting dalam suatu sistem telekomunikasi. Tapis digunakan untuk menyeleksi frekuensi yang akan dilewatkan dalam melakukan telekomunikasi. Perkembangan sistem telekomunikasi membuat penggunaan band frekuensi yang semakin meluas, sehingga frekuensi yang digunakan juga frekuensi yang tinggi pula. Tapis dapat dirancang secara sederhana menggunakan lumped element yang terdiri dari kapasitor, resistor, dan juga induktor. Namun tapis ini mempunyai keterbatasan yaitu hanya dapat digunakan pada frekuensi rendah saja dan tidak efektif untuk frekuensi tinggi. Tapis yang dapat digunakan pada frekuensi tinggi dapat dirancang menggunakan mikrostrip. Bentuk-bentuk tapis mikrostrip pun beranekaragam, salah satunya adalah square open loop resonator. Penelitian ini akan membahas tentang perancangan tapis dualband dengan metode square open loop resonator pada frekuensi $2100 \mathrm{MHz}$ menggunakan software CST Studio Suite 2016. Respon frekuensi yang dihasilkan oleh desain akhir dari tapis ini dapat meloloskan frekuensi pada rentang $1927 \mathrm{MHz}-2175 \mathrm{MHz}$ dan $3021 \mathrm{MHz}-3296$ MHz. Nilai insertion loss yang dihasilkan sebesar 1,4283 dB pada band bawah dan return loss sebesar 19,707 dB pada band bawah.
\end{abstract}

Kata Kunci : tapis, dualband bandpass filter, square open loop resonator,insertion loss, return loss

\begin{abstract}
Filter is an important component on the telecommunication system. Filter is used to select a certain range of frequency in communication process. The development of telecommunication system has been spread in frequency usage, the higher frequency is used to communicate. In simple form, filter can be designed using lumped component which consist of resistor, capacitor, and inductor. However, this form of filter can only be used in lower frequency and can't be effectively used in higher frequency range. Filter for higher frequency can be designed using microstrip. There are varieties of microstrip filter, one of them is square open loop resonator. This final project will discuss abut the design of dualband bandpass filter on the form of square open loop resonator in $2100 \mathrm{MHz}$ using CST Studio Suite 2016. The frequency response of the final design can pass the frequency in the range of $1927 \mathrm{MHz}-2175 \mathrm{Mhz}$ and $3021 \mathrm{MHz}-3296$ MHz. The insertion loss value is $1,4283 \mathrm{~dB}$ in lower band and return loss value is $19,707 \mathrm{~dB}$ in lower band.
\end{abstract}

Keywords : filter, dualband bandpass filter, square open loop resonator, insertion loss, return loss

\section{Pendahuluan}

Tapis (filter) merupakan salah satu komponen yang berperan penting dalam sistem komunikasi saat ini. Sistem telekomunikasi bekerja pada rentang frekuensi tertentu. Tapis berfungsi untuk melewatkan sinyal informasi yang berada pada wilayah frekuensi kerja yang dikehendaki [1-2]. Pada saat ini, frekuensi yang digunakan untuk melakukan komunikasi berada pada rentang yang tinggi. Tapis mikrostrip merupakan salah satu jenis tapis yang sering digunakan pada frekuensi tinggi [3]. Desain stub resonator populer untuk tapis frekuensi tinggi [4-5]. Beberapa desain telah diajukan untuk frekuensi sekitar $2100 \mathrm{MHz}$ untuk komunikasi selular, antara lain [6], namun gainnya masih cukup rendah, ataupun pada [7], namun dengan ukuran yang kurang kompak. Desain square open loop diajukan sebagai pendekatan lain yang dianggap cukup memadai [8-9].

Pada penelitian ini dibahas mengenai perancangan sebuah tapis mikrostrip. Tapis yang dirancang menggunakan resonator dengan bentuk square open loop. Tapis ini dirancang untuk melewatkan frekuensi pada wilayah kerja $2100 \mathrm{MHz}$ yang berada pada rentang 1920-2170 MHz dan juga band frekuensi atas yang berada pada rentang 3100 MHz. Terdapat 4 parameter desain yang digunakan dalam merancang tapis ini yaitu $\mathrm{L}_{1}, \mathrm{~L}_{2}, \mathrm{~g}_{1}, \mathrm{~g}_{2}$. Parameter $\mathrm{L}_{1}$ ditentukan melalui perhitungan sebelumnya, sementara 
parameter $\mathrm{L}_{2}, \mathrm{~g}_{1}, \mathrm{~g}_{2}$ merupakan nilai yang dipilih sendiri oleh penulis dengan mempertimbangkan hasil simulasi. Nilai insertion loss dan return loss yang dihasilkan juga akan diperhatikan dalam perancangan tapis.

\section{Metode}

\subsection{Langkah Penelitian}

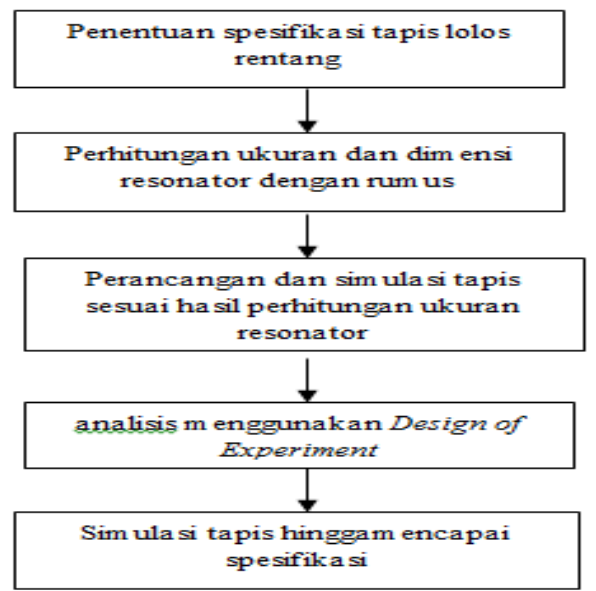

\section{Gambar 1. Langkah Perancangan Tapis}

Pada peneltian ini dijelaskan tentang proses perancangan tapis mikrostrip square open loop resonator. Perangkat lunak yang akan di gunakan adalah CST Studio Suite 2016. Secara umum langkah penelitian yang dilakukan ditunjukkan pada Gambar 1.

\subsection{Penentuan Spesifikasi Tapis}

Spesifikasi tapis square open loop resonator yang dirancang ditunjukkan pada Tabel 1. Sementara itu, material yang digunakan dalam perancangan tapis adalah Rogers 3210. Material tersebut mempunyai spesifikasi seperti pada Table 2 .

\section{Tabel 1. Spesifikasi Tapis}

\begin{tabular}{lll}
\hline No & Parameter & Spesifikasi \\
\hline 1 & Center Frequency & 2045 (band bawah), band atas mengikuti \\
2 & Bandwidth & $\begin{array}{l}250 \mathrm{MHz} \text { band bawah, band atas } \\
\text { mengikuti }\end{array}$ \\
& & $1 \mathrm{~dB}$ nominal \\
3 & Insetion Loss & $\geq 15 \mathrm{~dB}$ \\
4 & Return Loss & $1920<\mathrm{f}<2170$ pada band bawah, band \\
5 & Out of band rejection & atas mengikuti \\
& & $50 \mathrm{ohm}$ \\
\hline
\end{tabular}

Tabel 2. Spesifikasi Rogers 3210 [10]

\begin{tabular}{cc}
\hline Parameter & Spesifikasi \\
\hline Konstanta Dielektrik $\left(\varepsilon_{\mathrm{r}}\right)$ & 10,8 \\
Faktor Disipasi & 0,0027 \\
Tebal dielektik $(\mathrm{h})$ & $0,64 \mathrm{~mm}$ \\
Tebal konduktor $(\mathrm{t})$ & $0,035 \mathrm{~mm}$ \\
\hline
\end{tabular}

\subsection{Dimensi Resonator pada Tapis}

Tapis yang dirancang adalah tapis lolos rentang dengan metode square open loop resonator yang bekerja pada dualband yaitu 1920-2170 MHz, di mana frekuensi resonansinya berada pada frekuensi tengah yaitu 2045 MHz. Pada perancangan awal dilakukan perhitungan saluran transmisi yang meliputi:

- Lebar saluran transmisi (W) :

Untuk dapat menentukan lebar dari saluran transmisi mikrostrip, dapat digunakan persamaan berikut [9]:

$$
\begin{gathered}
\frac{W}{h}=\frac{8 e^{A}}{e^{2 A}-2} \\
A=\frac{Z_{o}}{60}\left[\frac{\varepsilon_{r}+1}{2}\right]^{0,5}+\frac{\varepsilon_{r}-1}{\varepsilon_{r}+1}\left[0,23+\frac{0,11}{\varepsilon_{r}}\right]
\end{gathered}
$$

$\varepsilon_{r}=10,8$$$
\text { sehingga diperoleh : }
$$$$
A=2,169814 \approx 2,17
$$

Kemudian nilai $A$ disubstitusi ke dalam persamaan $\frac{W}{h}=\frac{8 e^{A}}{e^{2 A}-2}$

Sehingga diperoleh nilai $\frac{W}{h}=0,937874$

$h$ (ketebalan) dari substrat Rogers 3210 adalah 0,64 mm, sehingga diperoleh nilai :

$\mathrm{W}=0,600239 \mathrm{~mm} \approx 0,6 \mathrm{~mm}$

- $\quad$ Permitivitas bahan dielektrik efektif $\left(\varepsilon_{\text {reff }}\right)$

Untuk mencari nilai permitivitas bahan dielektrik efektif dari bahan substrat, dapat digunakan persamaan [2]:

$$
\varepsilon_{r, \text { eff }}=\frac{\varepsilon_{r}+1}{2}+\frac{\varepsilon_{r}-1}{2}\left(1+\frac{10}{u}\right)^{-a . b}
$$

$a=1+\frac{1}{49} \ln \left[\frac{u^{4}+\left(\frac{u}{52}\right)^{2}}{u^{4}+0,432}\right]+\frac{1}{18,7} \ln \left[1+\left(\frac{u}{18,1}\right)^{3}\right]$

$\frac{w}{h}=u$, sehingga diperoleh :

$a=0,990963$

$$
b=0,564\left(\frac{\varepsilon_{r}-0,9}{\varepsilon_{r}+3}\right)^{0,053}
$$

$b=0,553628$

Kemudian nilai $a$ dan $b$ disubstitusikan ke dalam persamaan sehingga diperoleh nilai:

$$
\varepsilon_{r, e f f}=6.795339
$$

- Panjang gelombang $\left(\lambda_{g}\right)$

Untuk menentukan $\lambda_{g}$ dalam saluran transmisi mikrostrip digunakan Persamaan 2.35 [9].

$$
\begin{gathered}
\lambda_{g}=\frac{300}{f \text { resonansi }(G H z) \sqrt{\varepsilon_{r, \text { eff }}}} \\
\lambda_{g}=\frac{300}{2,045 \sqrt{6,795339}} \\
\lambda_{g}=56,27589 \approx 56 \mathrm{~mm}
\end{gathered}
$$


- $\quad$ Panjang resonator $(a)$

Untuk menentukan panjang resonator (a) pada saluran transmisi mikrostrip digunakan persamaan:

$$
a=\frac{\frac{1}{2} \lambda_{g}+\text { gap }}{4}+w
$$

Nilai gap yang digunakan dalam perancangan tapis adalah 0.6 dan nilai $w$ adalah 0.6. Kemudian nilai gap dan $w$ disubstitusikan ke dalam persamaan menjadi :

$a=\frac{\frac{1}{2}(56)+0.6}{4}+0.6$
$a=7.75 \mathrm{~mm}$

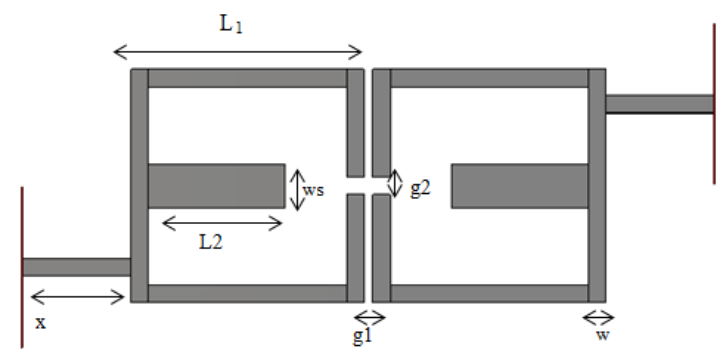

Gambar 2. Tapis square open loop resonator dan elemen penyusunnya

\section{Hasil dan Analisis}

Perancangan tapis dilakukan dengan metode Design of Experiment (DOE). Metode DOE digunakan dengan menghasilkan sebuah rumus yang dapat digunakan untuk memprediksi hasil simulasi yang dihasilkan. Metode Design of Experiment dilakukan dengan cara melakukan simulasi sebanyak $2^{\mathrm{n}}$, di mana $\mathrm{n}$ adalah jumlah parameter yang akan divariasikan dalam simulasi.

Terdapat 4 parameter yang divariasikan sehingga simulasi dilakukan sebanyak 16 kali. Awalnya simulasi dilakukan dengan penambahan dan pengurangan sebesar $0,5 \mathrm{~mm}$ pada $\mathrm{L}_{1}$ dan $\mathrm{L}_{2}$, serta penambahan dan pengurangan sebesar $0,5 \%$ pada $\mathrm{g}_{1}$ dan $\mathrm{g}_{2} .4$ parameter yang divariasikan tersebut merupakan faktor yang akan dilihat pengaruhnya pada parameter desain. Parameter desain terdiri atas 4 jenis yaitu $F_{1}$ (frekuensi tengah band bawah), $\mathrm{F}_{2}$ (frekuensi tengah band atas), $\mathrm{B}_{1}$ (bandwidth pada band bawah), dan $\mathrm{B}_{2}$ (bandwidth pada band atas). Nilai dari parameter faktor dapat ditunjukkan pada Tabel 3 .

Tabel 3. Parameter Desain

\begin{tabular}{lccccc}
\hline Faktor & $\begin{array}{c}\text { Ukuran } \\
\text { awal } \\
(\mathbf{m m})\end{array}$ & $\begin{array}{l}\text { Variasi } \\
\mathbf{m m}\end{array}$ & $\%$ & $\begin{array}{c}\text { Ukuran } \\
\text { setelah } \\
\text { ditambah } \\
(\mathbf{m m})\end{array}$ & $\begin{array}{c}\text { Ukuran } \\
\text { setelah } \\
\text { dikurangi } \\
(\mathbf{m m})\end{array}$ \\
\hline $\mathrm{L}_{1}$ & 7,75 & 0,5 & - & 8,25 & 7,25 \\
$\mathrm{~L}_{2}$ & 4,7 & 0,5 & - & 5,2 & 4,2 \\
$\mathrm{~g}_{1}$ & 0,6 & - & 0,5 & 0,63 & 0,57 \\
$\mathrm{~g}_{2}$ & 0,6 & - & 0,5 & 0,63 & 0,57 \\
\hline
\end{tabular}

\subsection{Penentuan Rumus untuk Prediksi}

Setelah melakukan simulasi sebanyak 16 kali, maka akan dicari nilai koefisien dari rumus yang akan dibuat. Penentuan nilai koefisien dilakukan pada parameter $\mathrm{F}_{1}, \mathrm{~F}_{2}, \mathrm{~B}_{1}, \mathrm{~B}_{2}$. Penentuan nilai koefisien dilakukan dengan mencari slope dari nilai rata-rata $\mathrm{F}_{1}, \mathrm{~F}_{2}, \mathrm{~B}_{1}, \mathrm{~B}_{2}$ saat $\mathrm{L}_{1}, \mathrm{~L}_{2}$, $\mathrm{g}_{1}, \mathrm{~g}_{2}$ bernilai positif atau negatif, seperti ditunjukkan pada Tabel 4-7.

Rumus perhitungan nilai slope adalah sebagai berikut:

$$
\text { slope }=\frac{\text { rerata nilai positif-rerata nilai negatif }}{2}
$$

\section{a. Penentuan Koefisien pada $F_{1}$}

Tabel 4. Contoh Penentuan Koefisien pada $F_{1}$

\begin{tabular}{ll|c}
\hline Kondisi & Nilai Rata-rata $F_{1}$ & Koefisien \\
\hline $\mathrm{L}_{1}+1$ & 2,0459625 & $-0,16321875$ \\
$\mathrm{~L}_{1}-1$ & 2,3724 & 0,00139375 \\
\hline $\mathrm{L}_{2}+1$ & 2,210575 & \\
$\mathrm{~L}_{2}-1$ & 2,2077875 & \\
\hline
\end{tabular}

\section{b. Penentuan Koefisien pada $\mathbf{F}_{2}$}

Tabel 5. Contoh Penentuan Koefisien pada $F_{2}$

\begin{tabular}{ll|c} 
Kondisi & Nilai Rata-rata $F_{2}$ & Koefisien \\
\hline $\mathrm{L}_{1}+1$ & 3,1822 & $-0,17804375$ \\
$\mathrm{~L}_{1}-1$ & 3,5382875 & $-0,09064375$ \\
$\mathrm{~L}_{2}+1$ & 3,2696 & \\
$\mathrm{~L}_{2}-1$ & 3,4508875 & \\
\hline
\end{tabular}

\section{c. Penentuan Koefisien untuk $B_{1}$}

Tabel 6. Koefisien dan rata-rata $B_{1}$

\begin{tabular}{ll|c}
\hline Kondisi & Nilai Rata-rata $B_{1}$ & Koefisien \\
\hline$L_{1}+1$ & 0,130625 & $-0,010175$ \\
$L_{1}-1$ & 0,150975 & $-0,0008625$ \\
\hline$L_{2}+1$ & 0,1399375 & \\
$L_{2}-1$ & 0,1416625 & \\
\hline
\end{tabular}

\section{d. Penentuan Koefisien untuk $B_{2}$}

Tabel 7. Koefisien dan rata-rata $B_{2}$

\begin{tabular}{ll|c}
\hline Kondisi & Nilai Rata-rata $B_{2}$ & Koefisien \\
\hline$L_{1}+1$ & 0,1042375 & $-0,01003125$ \\
$L_{1}-1$ & 0,1243 & 0,01434375 \\
\hline$L_{2}+1$ & 0,1286125 & \\
$L_{2}-1$ & 0,099925 & \\
\hline
\end{tabular}

\subsection{Penggunaan Rumus untuk Memprediksi Hasil Simulasi}

Rumus yang dihasilkan dari simulasi sebelumnya mempunyai nilai koefisien. Nilai koefisien dapat digunakan untuk menunjukkan parameter faktor yang besar pengaruhnya terhadap parameter respon. Semakin besar nilai koefisien, maka semakin besar pengaruhnya 
terhadap respon yang dihasilkan, begitu juga sebaliknya. Hubungan antara parameter faktor yang paling mempengaruhi respon dapat ditunjukkan pada Tabel 8.

Tabel 8. Penentuan Parameter Desain yang mempengaruhi Respon

\begin{tabular}{ccc}
\hline Respon & Nilai Koefisien Terbesar & Parameter Desain \\
\hline$F_{1}$ & 0,034366071 & $L_{1}{ }^{*} L_{2}{ }^{*} g_{2}$ \\
$F_{2}$ & 0,031926786 & $L_{2}{ }^{*} g_{1}{ }^{*} g_{2}$ \\
$B_{1}$ & 0,002389286 & $L_{1}{ }^{*} L_{2}{ }^{*} g_{1}$ \\
$B_{2}$ & 0,01434375 & $L_{2}$ \\
\hline
\end{tabular}

Berdasarkan Tabel 8, diketahui bahwa respon $F_{1}$ dipengaruhi oleh kombinasi ketiga parameter desain yaitu $\mathrm{L}_{1}, \mathrm{~L}_{2}$, dan $\mathrm{g}_{2}$. Respon $\mathrm{F}_{2}$ dipengaruhi oleh parameter desain $\mathrm{L}_{2}, \mathrm{~g}_{1}$, dan $\mathrm{g}_{2}$. Respon $\mathrm{B}_{1}$ dipengaruhi oleh parameter desain $\mathrm{L}_{1}, \mathrm{~L}_{2}$, dan $\mathrm{g}_{1}$. Respon $\mathrm{B}_{2}$ dipengaruhi oleh parameter desain $\mathrm{L}_{2}$. Setelah itu, dilakukan kembali prediksi rumus dengan mengubah nilai dari keempat parameter tersebut. Pertama-tama akan dilakukan prediksi rumus untuk 16 kali simulasi. Prediksi rumus yang pertama akan dilakukan dengan mengubah nilai parameter desain terlebih dahulu. Data pengubahan parameter desaindapat ditunjukkan pada Tabel 9.

Tabel 9. Parameter tapis setelah pengubahan $\mathbf{L}_{1}, \mathbf{L}_{2}, \mathbf{g}_{1}, \mathbf{g}_{2}$.

\begin{tabular}{ccccc}
\hline No. & Faktor & $\begin{array}{c}\text { Ukuran } \\
\text { awal }(\mathbf{m m})\end{array}$ & $\begin{array}{c}\text { Ukuran setelah } \\
\text { ditambah }(\mathbf{m m})\end{array}$ & $\begin{array}{c}\text { Ukuran setelah } \\
\text { dikurangi }(\mathbf{m m})\end{array}$ \\
\hline 1. & $\mathrm{L}_{1}$ & 7,75 & 8,3 & 7,2 \\
2. & $\mathrm{L}_{2}$ & 4,7 & 5,25 & 4,15 \\
3. & $\mathrm{g}_{1}$ & 0,6 & 0,612 & 0,588 \\
4. & $\mathrm{g}_{2}$ & 0,6 & 0,612 & 0,588 \\
\hline
\end{tabular}

Setelah didapatkan data seperti pada Tabel 9 maka akan dilakukan prediksi hasil simulasi terlebih dahulu. Setelah dilakukan prediksi, maka akan dilakukan juga simulasi sebanyak 16 kali. Data hasil prediksi rumus dan data hasil simulasi dapat ditunjukkan pada Tabel 10-11.

Tabel 10 Data hasil prediksi rumus (dalam GHz)

\begin{tabular}{rrrrrrrr}
\hline $\mathrm{L}_{1}$ & $\mathrm{~L}_{2}$ & $\mathrm{~g}_{1}$ & $\mathrm{~g}_{2}$ & $\mathrm{~F}_{1}$ & $\mathrm{~F}_{2}$ & $\mathrm{~B}_{1}$ & $\mathrm{~B}_{2}$ \\
\hline+ & + & + & + & 2,653 & 3,388 & 0,139 & 0,375 \\
+ & + & + & - & 2,624 & 3,446 & 0,141 & 0,377 \\
+ & + & - & + & 2,573 & 3,457 & 0,139 & 0,385 \\
+ & + & - & - & 2,579 & 3,335 & 0,138 & 0,383 \\
+ & - & + & + & 2,239 & 3,166 & 0,117 & 0,283 \\
+ & - & + & - & 2,212 & 3,145 & 0,115 & 0,287 \\
+ & - & - & + & 2,209 & 3,137 & 0,118 & 0,286 \\
+ & - & - & - & 2,183 & 3,117 & 0,116 & 0,290 \\
- & + & + & + & 2,569 & 3,410 & 0,137 & 0,342 \\
- & + & + & - & 2,536 & 3,378 & 0,137 & 0,345 \\
- & + & - & + & 2,539 & 3,388 & 0,135 & 0,347 \\
- & + & - & - & 2,507 & 3,357 & 0,135 & 0,350 \\
- & - & + & + & 2,206 & 3,111 & 0,117 & 0,264 \\
- & - & + & - & 2,218 & 3,119 & 0,119 & 0,266 \\
- & - & - & + & 2,220 & 3,126 & 0,117 & 0,267 \\
- & - & - & - & 2,194 & 3,101 & 0,118 & 0,269 \\
\hline
\end{tabular}

Berdasarkan hasil simulasi diatas dapat disimpulkan bahwa belum ada simulasi yang menghasilkan respon sesuai dengan spesifikasi yang diharapkan. Tetapi berdasarkan hasil simulasi tersebut dapat dilihat bahwa semakin panjang $\mathrm{L}_{1}$ maka frekuensi yang dihasilkan akan semakin kecil, begitu juga sebaliknya. Demikian juga pada $\mathrm{L}_{2}$, namun perubahan $\mathrm{L}_{2}$ dari nilai $+\mathrm{ke}-$ tidak berpengaruh signifikan pada frekuensi yang dihasilkan. Selain itu, pada $\mathrm{g}_{1}$ dapat disimpulkan bahwa semakin besar nilai g1 maka lebar bandwidth akan semakin besar. Sementara pada parameter faktor $\mathrm{g}_{2}$ dapat dilihat bahwa semakin besar nilai $\mathrm{g}_{2}$, maka bandwidth akan semakin kecil, begitu juga sebaliknya. Berdasarkan kesimpulan tersebut, maka dilakukan kembali simulasi sebanyak 4 kali. Pada simulasi ini $\mathrm{L}_{1}, \mathrm{~L}_{2}$, dan $\mathrm{g}_{1}$ akan bernilai sama sementara pada $\mathrm{g}_{2}$ akan dibuat variasi sebanyak 4 buah. Data perubahan nilai $\mathrm{L}_{1}, \mathrm{~L}_{2}, \mathrm{~g}_{1}, \mathrm{~g}_{2}$ dapat ditampilkan pada Tabel 12.

Tabel 12. Parameter tapis setelah pengubahan $L_{1}, L_{2}, g_{1}, g_{2}$.

\begin{tabular}{clcccc}
\hline No. & Faktor & $\begin{array}{c}\text { Variasi 17 } \\
(\mathbf{m m})\end{array}$ & $\begin{array}{c}\text { Variasi 18 } \\
(\mathbf{m m})\end{array}$ & $\begin{array}{l}\text { Variasi 19 } \\
(\mathbf{m m})\end{array}$ & $\begin{array}{l}\text { Variasi 20 } \\
(\mathbf{m m})\end{array}$ \\
\hline 1. & L1 & 8 & 8 & 8 & 8 \\
2. & L2 & 4,7 & 4,7 & 4,7 & 4,7 \\
3. & g1 & 0,588 & 0,588 & 0,588 & 0,588 \\
4. & g2 & 0,45 & 0,4 & 0,35 & 0,3 \\
\hline
\end{tabular}

Tabel 13. Hasil Simulasi Variasi 17 - Variasi 20

\begin{tabular}{lcccccccc}
\hline \multirow{2}{*}{ Variasi } & \multicolumn{9}{c}{ Band bawah } & \multicolumn{5}{c}{ Band atas } \\
& $F_{L} 1$ & $F_{U} 1$ & $F_{1}$ & $B_{1}$ & $F_{L} 2$ & $F_{U} 2$ & $F_{2}$ & $B_{2}$ \\
\hline 17 & 1,969 & 2,145 & 2,057 & 0,176 & 3,076 & 3,264 & 3,170 & 0,187 \\
18 & 1,956 & 2,154 & 2,055 & 0,198 & 3,060 & 3,274 & 3,167 & 0,214 \\
19 & 1,943 & 2,165 & 2,054 & 0,222 & 3,040 & 3,284 & 3,162 & 0,245 \\
20 & 1,927 & 2,175 & 2,051 & 0,248 & 3,021 & 3,296 & 3,159 & 0,276 \\
\hline
\end{tabular}

Simulasi pada Variasi 17-19 belum menghasilkan respon sesuai dengan spesifikasi yang diharapkan. Tetapi pada simulasi variasi 20 respon yang dihasilkan sudah mendekati spesifikasi yang ditetapkan yaitu pada frekuensi 1920-2170 MHz. Sehingga, desain akhir tapis yang telah memenuhi spesifikasi adalah desain pada variasi 20 (Tabel 13). Simulasi S11 dan S21 ditunjukkan pada Gambar 3. 


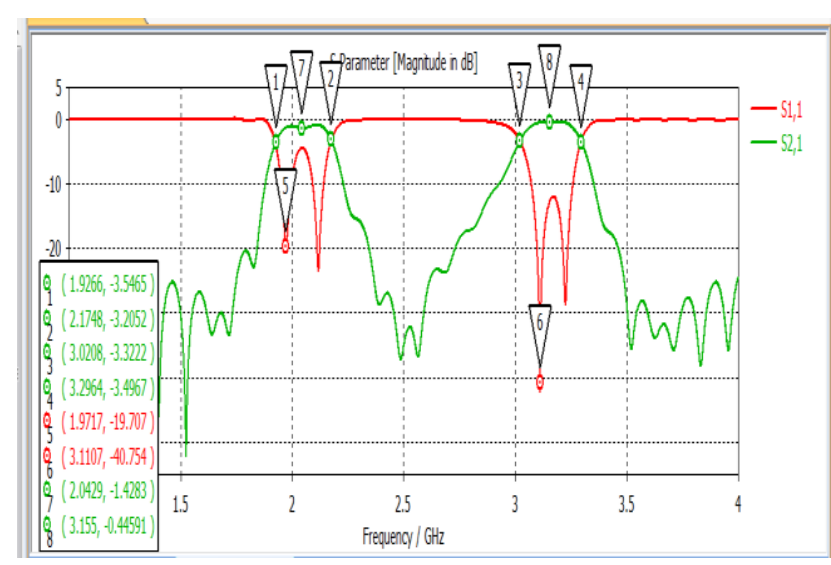

Gambar 3. Desain akhir tapis sesuai dengan Variasi 20.

\subsection{Evaluasi Desain Akhir Tapis}

Tabel 14 adalah perbandingan antara spesifikasi dan simulasi. Frekuensi kerja, bandwidth, insertion loss, return loss sudah memenuhi spesifikasi yang ditentukan.

Tabel 14 Perbandingan hasil simulasi dan spesifikasi tapis pada band bawah

\begin{tabular}{ccc}
\hline Parameter & Spesifikasi & Simulasi \\
\hline Frekuensi kerja $(\mathrm{MHz})$ & $1920-2170$ & $1927-2175$ \\
Bandwidth $(\mathrm{MHz})$ & 250 & 248,2 \\
Insertion Loss $(\mathrm{dB})$ & $1 \mathrm{~dB}$ nominal & $1,4 \mathrm{~dB}$ \\
Return Loss $(\mathrm{dB})$ & $\geq 15 \mathrm{~dB}$ & $19,7 \mathrm{~dB}$ \\
\hline
\end{tabular}

\section{Kesimpulan}

Penggunaan metode Design of Experiment (DOE) dilakukan untuk mengetahui efek dari penambahan dan pengurangan panjang dan persentase dari 4 paramater desain yaitu $\mathrm{L}_{1}, \mathrm{~L}_{2}, \mathrm{~g}_{1}$, dan $\mathrm{g}_{2}$. Setelah dilakukan pengurangan panjang pada parameter $\mathrm{L}_{1}$ dan $\mathrm{g}_{2}$, penambahan persentase pada parameter $\mathrm{g}_{1}$ dan $\mathrm{L}_{2}$ dengan nilai yang tetap, diperoleh frekuensi kerja yang mendekati spesifikasi yaitu pada rentang $1927 \mathrm{MHz}-2175 \mathrm{MHz}$ untuk band bawah dan $3021 \mathrm{MHz}$ - $3296 \mathrm{MHz}$ untuk band atas.Prediksi hasil simulasi juga dilakukan dengan menggunakan rumus. Rumus yang dihasilkan pada untuk memprediksi $\mathrm{F}_{1}$ mempunyai rata-rata galat relatif sebesar $12 \%, \mathrm{~F}_{2}$ sebesar 7\%, $\mathrm{B}_{1}$ sebesar $12,6 \%$, dan $\mathrm{B}_{2}$ sebesar $214 \%$. Error terbesar terdapat pada prediksi rumus pada $\mathrm{B}_{2}$.Penambahan dan pengurangan parameter desain berpengaruh pada respon frekuensi yang dihasilkan.
Pengurangan panjang $L_{1}$ akan menggeser frekuensi ke bawah. Penambahan besar $g_{1}$ akan memperlebar bandwidth dari tapis yang dihasilkan. Penambahan nilai pada $\mathrm{g}_{2}$ akan memperkecil bandwidth yang dihasilkan.

Penggunaan rumus dalam perhitungan dimensi resonator belum mendekati spesifikasi dari respon yang dikehendaki. Masih diperlukan simulasi sampai puluhan kali untuk dapat memperoleh hasil respon yang dapat memenuhi spesifikasi yang dikehendaki.

\section{Referensi}

[1]. Astuti, Dian Widi, dan Mudrik Alaydrus. "A bandpass filter based on square open loop resonators at 2.45 GHz." 3rd International Conference on Instrumentation, Communications, Information Technology, and Biomedical Engineering (ICICI-BME), 2013, hal. 147151.

[2]. Pozar, David M. Microwave Engineering. Edisi keempat. New Jersey: John Wiley \& Sons.2012.

[3]. Jia-Seng Hong. M.J Lancaster. Microstrip Filters for RF/Microwave Applications. New York: John Wiley \& Sons.2001.

[4]. Jian Xin Chen, Xiu Yin Zhang, Quan Xue. "Dualband Bandpass Filter Using Stub Loaded Resonator". IEEE Microwave and Wireless Components Letters. Vol. 17, N0. 8, August 2007.

[5]. Mudrik Alaydrus, Dian Widiastuti. "Studi Parameter Dualband Bandpass Filter Stub Loaded Square Open Loop Resonator". IncomTech, Jurnal Telekomunikasi dan Komputer, vol. 7, no.3, Februari 2017.

[6]. Subiyanto. "Perancangan dan Realisasi Dual-Band Band Pass Filter Frekuensi Uplink 3G (1920 MHz) Dan Downlink 3G (2110 MHZ) dengan Metode Square Open Loop Resonator". Tugas Akhir. Universitas Mercubuana Jakarta. 2013.

[7]. Moradi, Khatereh, and Saeid Nikmehr. "A dual-band dual-polarized microstrip array antenna for base stations." Progress In Electromagnetics Research, vol. 123, 2012, hal. 527-541.

[8]. Maharjan, R. K., B. Shrestha, and N. Y. Kim. "Compact microstrip square open-loop bandpass filter using open stub." Electronics Letters vol. 48, no. 6, 2012, hal. 333334.

[9]. Pozar, David.M. Microwave and RF Wireless System. New York: John Wiley \& Sons.2001.

[10]. https://www.rogerscorp.com [diakses 30 Agustus 2017] 